\title{
Major-element abundances on the surface of Mercury: Results from the MESSENGER Gamma-Ray Spectrometer
}

\author{
Larry G. Evans, ${ }^{1}$ Patrick N. Peplowski, ${ }^{2}$ Edgar A. Rhodes, ${ }^{2}$ David J. Lawrence, ${ }^{2}$ \\ Timothy J. McCoy, ${ }^{3}$ Larry R. Nittler, ${ }^{4}$ Sean C. Solomon, ${ }^{4,5}$ Ann L. Sprague, ${ }^{6}$ \\ Karen R. Stockstill-Cahill, ${ }^{3}$ Richard D. Starr, ${ }^{7}$ Shoshana Z. Weider, ${ }^{4}$ William V. Boynton, ${ }^{6}$ \\ David K. Hamara, ${ }^{6}$ and John O. Goldsten ${ }^{2}$
}

Received 2 July 2012; revised 7 September 2012; accepted 9 September 2012; published 2 November 2012.

[1] Orbital gamma-ray measurements obtained by the MESSENGER spacecraft have been analyzed to determine the abundances of the major elements $\mathrm{Al}, \mathrm{Ca}, \mathrm{S}, \mathrm{Fe}$, and $\mathrm{Na}$ on the surface of Mercury. The Si abundance was determined and used to normalize those of the other reported elements. The $\mathrm{Na}$ analysis provides the first abundance estimate of $2.9 \pm 0.1 \mathrm{wt} \%$ for this element on Mercury's surface. The other elemental results $(\mathrm{S} / \mathrm{Si}=0.092 \pm 0.015, \mathrm{Ca} / \mathrm{Si}=0.24 \pm 0.05$, and $\mathrm{Fe} / \mathrm{Si}=0.077 \pm 0.013)$ are consistent with those previously obtained by the MESSENGER X-Ray Spectrometer, including the high sulfur and low iron abundances. Because of different sampling depths for the two techniques, this agreement indicates that Mercury's regolith is, on average, homogenous to a depth of tens of centimeters. The elemental results from gamma-ray and X-ray spectrometry are most consistent with petrologic models suggesting that Mercury's surface is dominated by Mg-rich silicates. We also compare the results with those obtained during the MESSENGER flybys and with ground-based observations of Mercury's surface and exosphere.

Citation: Evans, L. G., et al. (2012), Major-element abundances on the surface of Mercury: Results from the MESSENGER Gamma-Ray Spectrometer, J. Geophys. Res., 117, E00L07, doi:10.1029/2012JE004178.

\section{Introduction}

[2] The MErcury Surface, Space ENvironment, GEochemistry, and Ranging (MESSENGER) spacecraft was launched on 3 August 2004, made three flybys of Mercury in 2008-2009, and achieved orbit around Mercury on 18 March 2011 to begin a primary orbital mission of 1 (Earth) year. One of the measurement objectives of the mission is to characterize the surface composition of the planet, and to that end the spacecraft carries a suite of geochemical remote-sensing instruments [Solomon et al., 2007] that includes a Gamma-

\footnotetext{
${ }^{1}$ Computer Sciences Corporation, Lanham-Seabrook, Maryland, USA.

${ }^{2}$ The Johns Hopkins University Applied Physics Laboratory, Laurel, Maryland, USA.

${ }^{3}$ Department of Mineral Sciences, National Museum of Natural History, Smithsonian Institution, Washington, D. C., USA.

${ }^{4}$ Department of Terrestrial Magnetism, Carnegie Institution of Washington, Washington, D. C., USA.

${ }^{5}$ Lamont-Doherty Earth Observatory, Columbia University, Palisades, New York, USA.

${ }^{6}$ Lunar and Planetary Laboratory, University of Arizona, Tucson, Arizona, USA.

${ }^{7}$ Department of Physics, Catholic University of America, Washington, D. C., USA.

Corresponding author: L. G. Evans, Computer Sciences Corporation, 7900 Harkins Rd., Lanham-Seabrook, MD 20706, USA.

(larry.g.evans@nasa.gov)

(C)2012. American Geophysical Union. All Rights Reserved. 0148-0227/12/2012JE004178
}

Ray and Neutron Spectrometer (GRNS). The Gamma-Ray Spectrometer (GRS) subsystem is designed to measure gamma rays in the energy range $60 \mathrm{keV}$ to $9 \mathrm{MeV}$ [Goldsten et al., 2007]. Unlike other geochemical remote-sensing measurements that are sensitive only to the uppermost surface layer $(<100 \mu \mathrm{m})$, orbital gamma-ray spectroscopy can measure elemental abundances in the top tens of centimeters beneath a planet's surface. The gamma rays are emitted from the decay of long-lived radioactive species and from the nuclear interactions of galactic cosmic ray (GCR) particles with the planetary materials. The interactions of secondary neutrons with atomic nuclei produce a majority of the gamma rays. The number of neutrons made by GCR particles, averaged over the solar cycle, is about 9 neutrons per incident GCR particle [Evans et al., 1993]. The primary modes of gamma-ray production are inelastic-scatter reactions with fast $(>1 \mathrm{MeV})$ neutrons, neutron capture reactions with thermal $(\sim 0.02 \mathrm{eV})$ neutrons, and activation by both proton and neutron interactions.

[3] Neutrons with sufficient energy can excite a nucleus to a higher energy state and exit with reduced energy, a process known as inelastic scattering. The excited nucleus decays with a characteristic half-life (typically a very small fraction of a second, e.g., $10^{-12} \mathrm{~s}$ ) to a lower state, usually through the emission of a gamma ray. Inelastic scattering emission is abbreviated as ${ }^{\mathrm{A}} \mathrm{X}\left(\mathrm{n}, \mathrm{n}^{\prime} \gamma\right){ }^{\mathrm{A}} \mathrm{X}$, where $\mathrm{n}$ and $\mathrm{n}^{\prime}$ are the initial and final energies of the neutron, $A$ is the atomic mass, and $\mathrm{X}$ the element. Another type of scatter reaction 
that includes the emission of an alpha particle $(\alpha)$ is denoted as ${ }^{A} X_{Z}\left(n, n^{\prime} \alpha \gamma\right){ }^{A-4} X_{Z-2}$, where $Z$ is the atomic number, e.g., ${ }^{16} \mathrm{O}_{8}\left(\mathrm{n}, \mathrm{n}^{\prime} \alpha \gamma\right){ }^{12} \mathrm{C}_{6}$. The bulk composition of the planet's surface does not strongly affect the relative production rates for inelastic scatter reactions, but does strongly affect the moderation of neutrons from $\mathrm{MeV}$ to thermal $(\mathrm{eV})$ energies. Neutrons with thermal energies can be captured by a nucleus, which puts the new isotope into an excited state that can rapidly decay to a lower level with the emission of a gamma ray. This reaction is abbreviated as ${ }^{\mathrm{A}} \mathrm{X}(\mathrm{n}, \gamma){ }^{\mathrm{A}+1} \mathrm{X}$, and the new isotope can also be radioactive and decay with a characteristic half-life that is typically much longer than the first decay. This process is termed neutron activation. The gamma rays emitted by these interactions have characteristic energies that can be used to identify the nuclides involved, and their fluxes can be related to the concentrations. Gamma-ray emission also occurs as a result of nuclear interactions with the gamma-ray detector and materials surrounding the detector, and from material in the spacecraft [Peplowski et al., $2012 \mathrm{~b}]$. The elements that produce these background emissions can include the same elements as those on the surface of Mercury. An understanding of the sources and intensities of background gamma rays is needed to subtract their contribution to the measurements correctly and to determine accurately the surface composition of Mercury. Here we discuss the GRS instrument, measurements, analysis, and result for the abundances of the major elements $\mathrm{Si}, \mathrm{Al}, \mathrm{Ca}$, $\mathrm{S}, \mathrm{Fe}$, and $\mathrm{Na}$.

\section{MESSENGER Gamma-Ray Spectrometer}

[4] The GRS sensor has been described in detail by Goldsten et al. [2007], and its characteristics will only be summarized here. It consists of a high-purity n-type germanium crystal that is actively cooled to cryo-temperatures $(<90 \mathrm{~K})$ by a miniature Stirling-cycle cooler. The crystal is contained in an aluminum cryostat that is suspended by Kevlar strings. It measures gamma-ray photons in the energy range $60 \mathrm{keV}$ to $9 \mathrm{MeV}$. The Ge crystal is a closed-end coaxial detector approximately $5 \mathrm{~cm}$ in diameter and $5 \mathrm{~cm}$ in length. It has an intrinsic efficiency of $9 \%$ at $1332 \mathrm{keV}$. The gamma-ray measurements are digitized by a 14-bit analog-to-digital converter into 16,384 pulse-height channels. The mechanical cryocooler is a Ricor K508 rotary Stirling-cycle unit with a mass of $450 \mathrm{~g}$, including motor drive electronics. In order to provide a lifetime margin for the planned one Earth-year orbit of Mercury, a He fill pressure was chosen to yield a nominal mean time to failure of $\sim 12,000 \mathrm{~h}$.

[5] The energy resolution of a GRS is one of the most important parameters for scientific investigations. This quantity is usually expressed as the full width at half-maximum (FWHM) of the $1332 \mathrm{keV}$ peak from the decay of ${ }^{60} \mathrm{Co}$. The final preflight measurements of the energy resolution of the detector system gave a FWHM of $3.5 \mathrm{keV}$. It was expected that the energy resolution would degrade over time due to interactions of high-energy GCRs and solar charged particles with the detector crystal. A FWHM measurement at a similar energy $(1368 \mathrm{keV})$ during the cruise phase of the mission, about three months after launch, gave a value of $3.7 \mathrm{keV}$ [Goldsten et al., 2007]. The detector was annealed periodically during the mission to help ameliorate the effects of radiation damage. This procedure removed some, but not all, of the radiation damage accumulated during the 6.6 year interplanetary cruise to Mercury. The resolution at $1368 \mathrm{keV}$ during the orbital measurements reported here was $\mathrm{FWHM}=4.8 \mathrm{keV}$.

[6] The GRS is surrounded by an anticoincidence shield (ACS) of borated plastic scintillator (BC454) coupled to a $7.6 \mathrm{~cm}$ photomultiplier tube. The shield allows events that are detected in both the shield and the Ge crystal to be removed (vetoed), thus reducing the continuum background from GCRs, and also shields the detector from thermal neutrons emitted from the planet. Since both the raw gamma-ray spectrum and the vetoed spectrum are measured simultaneously, the decrease in the continuum can be measured directly: a factor of three at $3 \mathrm{MeV}$ and a factor of seven at $8 \mathrm{MeV}$ [Goldsten et al., 2007; Peplowski et al., 2011b].

\section{Summing of Spectra}

[7] The sensitivity of orbiting gamma-ray experiments is limited by the photon flux from the surface of the planet. Many hours of accumulated spectra are required in order to obtain spectra with counting statistics sufficient for peak analysis. Typical count rates on Mars Odyssey [Boynton et al., 2007] were about $190 \mathrm{c} / \mathrm{s}$, but less than $4 \%$ of these counts were measured in discrete line peaks, and the rest were in the continuum [Evans et al., 2006]. Less than 40 of the more than 300 discrete line peaks measured were gamma rays originating from Mars that could be used to determine surface elemental abundances. Mars Odyssey was in a $400 \mathrm{~km}$ circular orbit, so all the measurements could be summed into a single planetary spectrum. In contrast, MESSENGER is in a highly eccentric orbit, and only those GRS measurements taken near periapsis in the northern hemisphere are useful for summing to obtain the planetary signal [Peplowski et al., 2011a]. For our analysis we used planetary spectra acquired at altitudes $<2000 \mathrm{~km}$, corresponding to a total accumulation time per $12 \mathrm{~h}$ orbit of about 45-50 min. A GRS data processing system developed at the University of Arizona [Boynton et al., 2007] was used to produce spectral sums of GRS data.

[8] Prior to spectral summing, corrections were applied to each individual $60 \mathrm{~s}$ spectrum. The electronic gain and offset for each spectrum were adjusted to a common energy scale to allow the summed spectra to have the best possible energy resolution. The first-order gain correction was related to temperature. Calibration spectra taken over a wide range of temperatures before launch were used to determine the gain correction as a function of temperature (from $-30^{\circ}$ to $64^{\circ} \mathrm{C}$ ), which was fit to a fifth-order polynomial whose coefficient values were incorporated into the GRS data processing scheme [Peplowski et al., 2012a]. The pulse-processing electronics design eliminated most of the electronic offset. All temperature-corrected spectra were adjusted to a common linear scale of $0.6 \mathrm{keV} / \mathrm{channel}$ and a zero offset. Some residual nonlinearity remained in the data but did not interfere with peak identifications.

[9] Individual gamma-ray spectra can be corrupted for a number of reasons, including changes in the detector high voltage, large temperature changes, and solar particle events (SPEs). As the Sun became more active in late 2011 and early 2012, the latter events became more numerous. Bad data flags were assigned to individual spectra, and the default for 


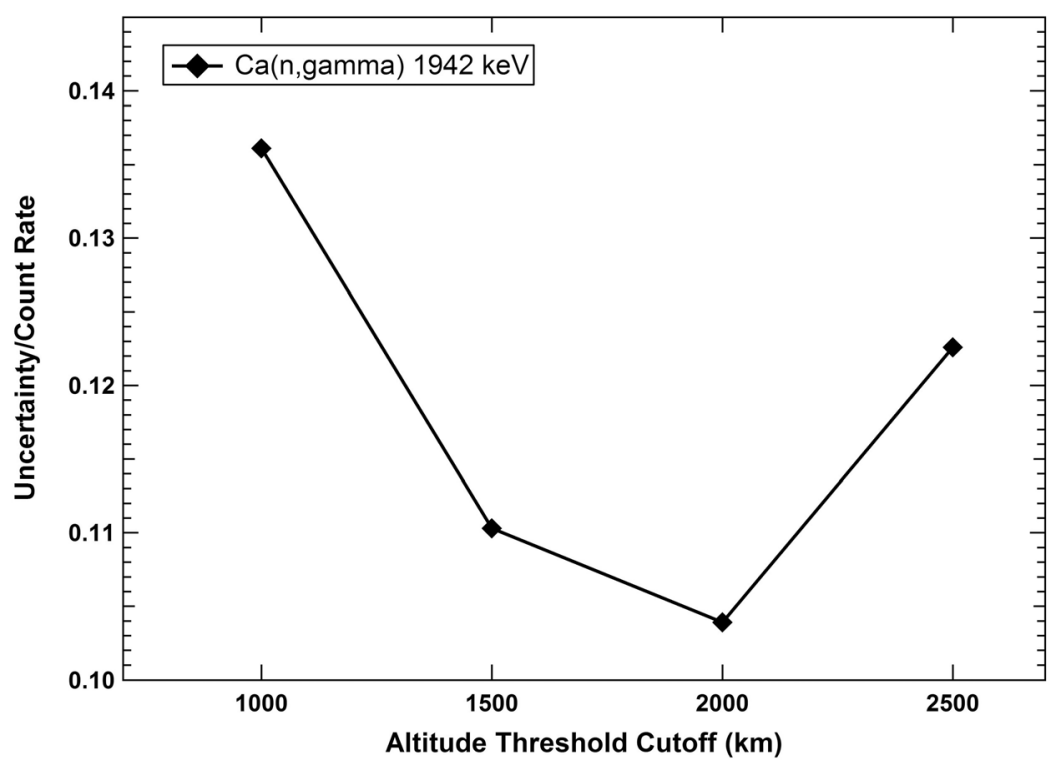

Figure 1. The variation of the uncertainty to peak count rates as a function of the low-altitude threshold for one example peak: $\mathrm{Ca}(\mathrm{n}, \gamma) 1942 \mathrm{keV}$ peak.

summing spectra was set to exclude these spectra. During the first three Mercury sidereal days (177 Earth days) of MESSENGER's orbital mission, the data flagged as bad consisted of about $10 \%$ of the total. The query tool used to obtain summed spectra could be set to include bad data during the selection process, e.g., to study spectra accumulated during SPEs.

[10] The GRS data processing system provides a means of accumulating summed spectra with a variety of different criteria. Accessible spectra include raw data for both the Ge detector and the ACS, as well as anticoincidence gammaray data. Data can be either uncalibrated or energy calibrated. The software allows summing of calibrated spectra for selected time intervals, latitude-longitude grids, and altitude ranges. For most of the analyses reported here, standard spectra were accumulated for the period 29 March 2011 through 24 September 2011. A large SPE occurred on 4 June 2011 and caused some long-lived activation of spacecraft and local materials that interfered with the analysis of the $\mathrm{Fe}$ $847 \mathrm{keV}$ gamma-ray peak. The analysis for this particular peak was therefore limited to spectra collected over the first Mercury sidereal day of MESSENGER's primary mission, from 29 March 2011 through 27 May 2011. The use of an integral number of sidereal days of data acquisition ensures uniform coverage of the surface for all longitudes.

[11] Due to MESSENGER's highly eccentric orbit, the choice of a summed spectrum to represent the planetary signal and one to represent the background is not straightforward. We take the background spectrum as an accumulation for altitudes greater than $14,000 \mathrm{~km}$, where the solid angle subtended by the planet from the spacecraft is less than $0.06 \mathrm{sr}$. As in previous work [Peplowski et al., 2011b], data for altitudes less than $2000 \mathrm{~km}$ were summed to produce a low-altitude spectrum containing the planetary signal. The periapsis of the orbit varied from $\sim 200 \mathrm{~km}$ to $\sim 490 \mathrm{~km}$ [McAdams et al., 2007]. The average altitude for the lowaltitude spectrum was $980 \mathrm{~km}$, and the solid angle at that altitude was $1.88 \mathrm{sr}$. The choice of low-altitude cutoff represents a compromise; at lower altitudes the planetary signal-to-background ratio is higher, but there is a shorter accumulation time and higher statistical uncertainty. Analysis of summed spectra for low-altitude thresholds of 1000 to $2500 \mathrm{~km}$ showed that for most peaks of interest, the cutoff of $2000 \mathrm{~km}$ was the best value. For example, Figure 1 shows the variation of the uncertainty in peak count rates for the $\mathrm{Ca}(\mathrm{n}, \gamma) 1942 \mathrm{keV}$ peak as a function of the lowaltitude threshold. There were some exceptions; weak Fe neutron capture peaks, in particular, could not be detected above background with a $2000 \mathrm{~km}$ threshold but could be analyzed with a lower-altitude cutoff.

[12] The accumulation time for the standard low-altitude spectrum was $9.91 \times 10^{5} \mathrm{~s}$ or 11.5 days and was $4.27 \times 10^{6} \mathrm{~s}$ or 49.4 days for the high-altitude spectrum. From the two time-normalized spectra shown in Figure 2, it can be seen that most of the peaks in the low-altitude spectrum have corresponding peaks in the high-altitude spectrum. As discussed by Peplowski et al. [2011b], the background count rate for natural radioactive elements present in spacecraft materials is constant with altitude and can be simply subtracted from the low-altitude count rate. The background for nonradioactive elements is due to interactions in the spacecraft and local materials both from GCRs and from neutrons originating in the planet. The GCR-induced background decreases with decreasing altitude as the planet blocks more of the GCR flux, whereas the planetary neutron background increases with decreasing altitude. This dependence on altitude was used to separate the background contributions for aluminum [Peplowski et al., 2012b], but the procedure did not work for other elements. The GRS sensor housing and structure are constructed mainly of $\mathrm{Mg}$ with some $\mathrm{Al}$ and $\mathrm{Fe}$, which limits the ability of the GRS to measure these elements from Mercury. Determination of abundances was possible for Al [Peplowski et al., 2012b] and $\mathrm{Fe}$ (see below), but not $\mathrm{Mg}$, for which the primary gamma 


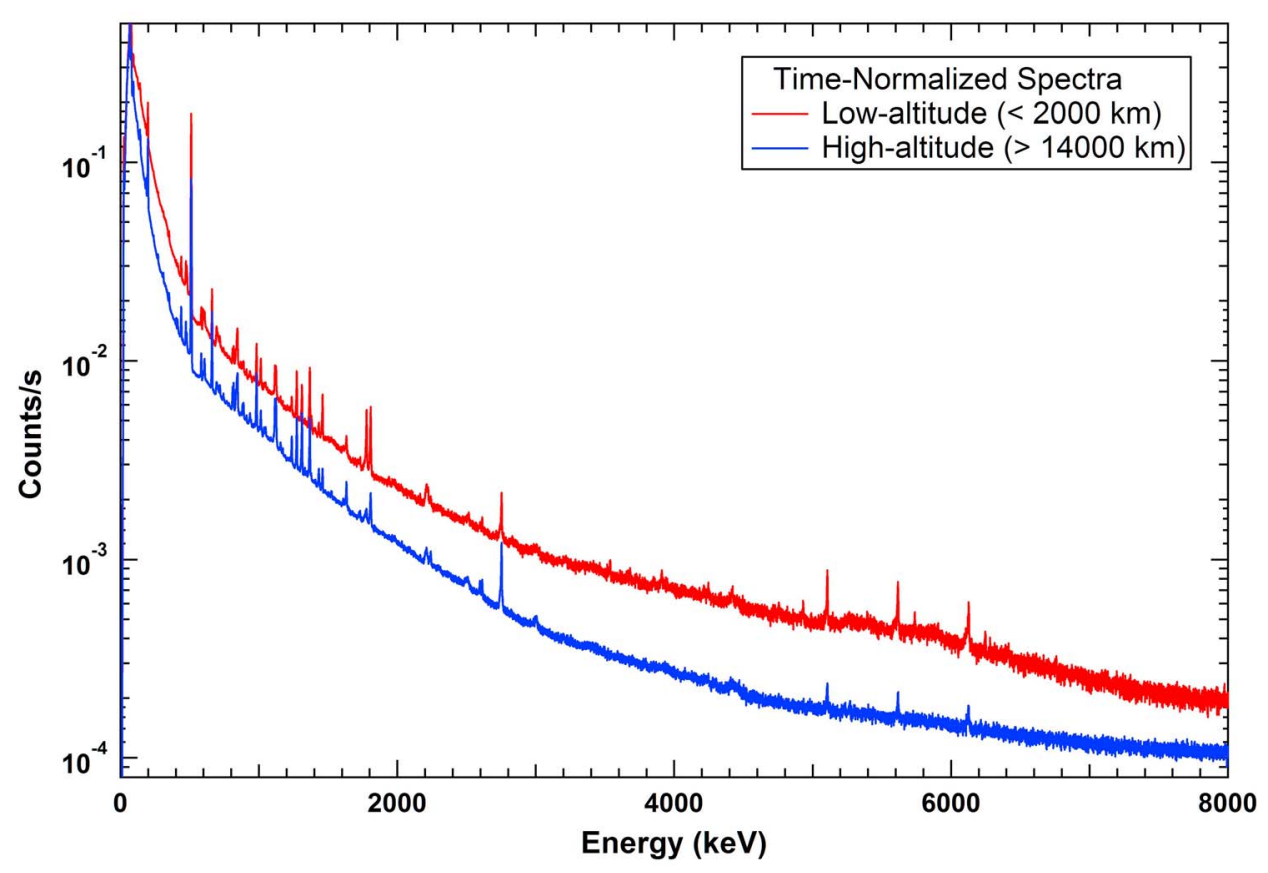

Figure 2. Comparison of the standard time-normalized low- and high-altitude GRS spectra accumulated from orbit of Mercury acquired between 29 March 2011 and 24 September 2011.

rays are subject to interfering peaks from numerous detector materials.

\section{Peaks and Other Features}

[13] The vast majority of counts in a GRS spectrum form a fairly smoothly varying continuum (Figure 2). This continuum has a number of sources, including gamma rays that are scattered in the planetary regolith and in the Ge detector, and bremsstrahlung from charged particles. The charged particles that interact in the shield are vetoed from the anticoincidence spectrum. The continuum under a peak or a group of peaks is usually determined by fitting a slowly varying low-order polynomial to portions of the spectra around the peaks that contain no noticeable peaks. Superimposed on the continuum are a large number of discrete gamma-ray peaks (Figure 2) most of which have a Gaussian shape with a low-energy tail due to trapping effects and charge-collection losses in the detector. The extent of this tailing increases with time in space because of radiation damage [Brückner et al., 1991]. The tail is fit with an exponential that joins smoothly to the Gaussian shape. The width of these Gaussian-shaped peaks increases slowly and systematically with increasing energy. Calibration of the energy dependence of spectral resolution can be used to help fit weak peaks [Evans et al., 2006]. Gamma rays with energies greater than $1022 \mathrm{keV}$ can interact in the detector through a process known as pair production that results in the production of two $511 \mathrm{keV}$ photons. One or both of these photons can escape the detector, producing gamma-ray peaks at the full-energy peak minus $511 \mathrm{keV}$ (termed the single-escape peak) and at the full-energy peak minus $2 \times 511 \mathrm{keV}$ (termed the double-escape peak).
[14] Some peaks are further broadened because the gamma ray is emitted while the excited nucleus is recoiling from an inelastic scatter interaction, a process known as Doppler broadening. In solid materials, gamma rays that are emitted from excited levels with lifetimes less than $\sim 0.5 \mathrm{ps}$ are Doppler broadened. Typically, Doppler-broadened peaks are symmetric in shape, as the broadening is much larger than the width of the Gaussian peak plus tailing. Example Dopplerbroadened peaks used in this analysis are the $2211 \mathrm{keV}$ aluminum and $2230 \mathrm{keV}$ sulfur peaks described below.

[15] Interactions of fast $(>1 \mathrm{MeV})$ neutrons with the $\mathrm{Ge}$ nuclei in the detector produce irregularly shaped peaks when the energy from the de-excitation of an excited level is summed with some of the recoil energy of the Ge nucleus. This summation results in a peak that has an approximately Gaussian shape below the excitation energy and a slowly decreasing tail at higher energies. These are called sawtooth peaks because of their shape. One particular sawtooth peak at $834 \mathrm{keV}$ is important in the analysis of the iron inelastic peak at $847 \mathrm{keV}$.

[16] To extract useful information from summed gammaray spectra, the integrated areas beneath important peaks must be determined. Analysis software originally developed for the Mars Odyssey mission [Boynton et al., 2007] was used to determine peaks areas from the GRS spectra. The software allows fitting of up to 10 peaks simultaneously in a portion of the spectrum. The ability of this software to fit regular (Gaussian shaped), Doppler broadened, and sawtooth peaks simultaneously [Evans et al., 2006] is particularly useful. Examples of these fits are discussed below for particular gamma rays used in determining the abundances of major elements on Mercury's surface. The integrated peak areas are corrected for data acquisition time and detector live- 
Table 1. Model Elemental Abundances Used for the Forward Calculations and Expected Count Rates From the Forward Calculations $^{\mathrm{a}}$

\begin{tabular}{|c|c|c|}
\hline Element & Concentration & $\mathrm{C} / \mathrm{min}$ \\
\hline $\mathrm{H}$ & $50 \mathrm{ppm}$ & \\
\hline $\mathrm{C}$ & $50 \mathrm{ppm}$ & \\
\hline $\mathrm{O}$ & $42.30 \%$ & \\
\hline $\mathrm{Na}$ & $0.80 \%$ & 0.439 \\
\hline $\mathrm{Mg}$ & $12.50 \%$ & \\
\hline $\mathrm{Al}$ & $5.65 \%$ & \\
\hline $\mathrm{Si}$ & $24.60 \%$ & I: 3.40 \\
\hline $\mathrm{Si}$ & $24.60 \%$ & C: 0.232 \\
\hline $\mathrm{P}$ & $30 \mathrm{ppm}$ & \\
\hline $\mathrm{S}$ & $4.00 \%$ & I: 0.331 \\
\hline $\mathrm{S}$ & $4.00 \%$ & C: 0.128 \\
\hline $\mathrm{Cl}$ & $0.15 \%$ & \\
\hline $\mathrm{Ar}$ & $10 \mathrm{ppm}$ & \\
\hline $\mathrm{K}$ & $0.12 \%$ & \\
\hline $\mathrm{Ca}$ & $4.80 \%$ & I: 0.0380 \\
\hline $\mathrm{Ca}$ & $4.80 \%$ & C: 0.108 \\
\hline $\mathrm{Ti}$ & $0.70 \%$ & \\
\hline $\mathrm{Cr}$ & $0.20 \%$ & \\
\hline $\mathrm{Mn}$ & $0.35 \%$ & \\
\hline $\mathrm{Fe}$ & $3.70 \%$ & I: 0.687 \\
\hline $\mathrm{Fe}$ & $3.70 \%$ & C: 0.210 \\
\hline Co & $500 \mathrm{ppm}$ & \\
\hline $\mathrm{Ni}$ & $500 \mathrm{ppm}$ & \\
\hline $\mathrm{Zn}$ & $50 \mathrm{ppm}$ & \\
\hline $\mathrm{Sm}$ & $10.3 \mathrm{ppb}$ & \\
\hline $\mathrm{Eu}$ & $3.9 \mathrm{ppb}$ & \\
\hline $\mathrm{Gd}$ & $14.1 \mathrm{ppb}$ & \\
\hline $\mathrm{Hg}$ & $1 \mathrm{ppm}$ & \\
\hline $\mathrm{Th}$ & $2.2 \mathrm{ppb}$ & \\
\hline $\mathrm{U}$ & $0.9 \mathrm{ppb}$ & \\
\hline
\end{tabular}

${ }^{\mathrm{a}} \mathrm{C} / \mathrm{min}$ denotes counts per minute; I denotes inelastic scatter gamma rays, and $\mathrm{C}$ denotes capture gamma rays.

time to determine the count rate at the detector. The live-time was determined using a pulser signal that inserted into the spectrum [Goldsten et al., 2007]. The correction values for the standard low-altitude and high-altitude spectra are, respectively, 0.88 and 0.90 .

\section{Forward Calculations}

[17] Due to the complexity of the process that produces planetary gamma rays from stable elements, it is not possible to relate directly the measured peak intensities to elemental abundances on the surface of Mercury. Instead, for gamma rays produced by neutron interactions, peak intensities must be compared with those predicted by a forward model calculation. The forward calculation depends on the flux and energy spectrum of incident cosmic rays, the assumed composition of the regolith, and the properties of the gammaray detector. The production of neutrons was modeled with the Monte Carlo N-Particle eXtended code (MCNPX) for an influx of GCRs [Waters, 2002; McKinney et al., 2006]. The composition of the regolith used for the calculation is shown in Table 1 and was selected on the basis of results from laboratory modeling, MESSENGER X-Ray Spectrometer (XRS) measurements of major elements on Mercury [Nittler et al., 2011], GRS measurements of radioactive element abundances [Peplowski et al., 2011b], and Neutron Spectrometer (NS) measurements [Lawrence et al., 2010]. In formulating a model composition two factors are most important for the forward calculations: the average atomic mass of the regolith and the macroscopic thermal neutron absorption cross section. The former has the greatest effect on the fast neutron distribution [Gasnault et al., 2001], and the latter has the greatest effect on the thermal neutron flux [Feldman et al., 2000]. The elements that have the largest effect on the neutron spectral and spatial distributions are hydrogen, elements of high atomic mass, and elements with large thermal neutron cross sections, such as $\mathrm{Fe}$ and $\mathrm{Ti}$. The model was also constrained by the NS measurements of the thermal neutron flux and XRS measurements of Fe and Ti [Lawrence et al., 2010; Nittler et al., 2011]. The model composition used for the forward calculations (Table 1) has an average atomic mass of 24.4 and a macroscopic thermal neutron cross section of $53 \times 10^{-4} \mathrm{~cm}^{2} / \mathrm{g}$. This value is within the range determined from the NS flyby measurements, though near the lower end [Lawrence et al., 2010]. There are some elements in the model included at very low abundances that do not affect the neutron calculations but may be relevant to possible future models. The output of MCNPX is the predicted flux of neutrons as a function of energy, depth, and emission angle. From this output and the cross sections for gamma-ray production, the flux of discrete gamma rays at the surface was calculated as a function of emission angle. For inelastic scatter reactions the production cross sections as a function of energy are required. For gamma rays produced by neutron capture, the cross sections for thermal neutron capture for all elements are assumed to vary inversely with velocity of the neutron. Only changes in composition that would change substantially either the atomic mass or the macroscopic thermal neutron cross section would change the neutron distributions and require new forward calculations.

[18] For each individual measurement in a spectral sum, a vector was determined between the detector and each location on the surface of Mercury that is visible to the detector; that vector defines the emission angle for that location. The predicted flux at the spacecraft is the sum of all fluxes from the surface adjusted on the basis of orbital geometry, i.e., spacecraft altitude and attitude. Finally, the calculated gamma-ray flux at the spacecraft was converted to counts in the detector on the basis of prelaunch measurements and calculations of the attenuation through parts of the spacecraft and local material and the detector efficiency as a function of incident angle and energy [Kim et al., 2006; Boynton et al., 2007; Peplowski et al., 2012a]. The process of making these calculations involves many factors, as the detector views a large area on the surface of the planet that varies with altitude and as different viewing angles from the detector have different efficiencies. From the forward model the expected counts in the detector were calculated for each spectrum (e.g., accumulation times of $60 \mathrm{~s}$ near the planet) for every location on the planetary surface on a grid of cells of dimension $0.5^{\circ}$ latitude by $0.5^{\circ}$ longitude. The location of the spacecraft over the surface at the midpoint of each accumulation time interval was calculated, and the vectors from each cell on the surface to the spacecraft were ascertained to determine the appropriate angle for surface gamma-ray flux.

[19] At the end of this process, each accumulated gammaray spectrum had associated with it a model calculation of the expected counts from each of approximately 100 gammaray lines of interest, not all of which are necessarily measured in the spectra. The abundance of an element for that spectrum was then determined by adjusting the model 
abundance by the ratio of the observed counts (minus any background) to the modeled counts for a particular gammaray peak. For elements with multiple gamma-ray lines, an average was calculated (weighted by the inverse square of the uncertainties for the individual results).

[20] The absolute GCR flux varies with time and is not well characterized, so in GRS analyses the results are often normalized to some known elemental abundance [Boynton et al., 2007]. For Mars Odyssey, the results were normalized to Si determined by the Mars Pathfinder silicon surface measurement of $20.95 \mathrm{wt} \% \mathrm{Si}$ [Boynton et al., 2007]. There is no comparable ground truth value for Mercury, but $\mathrm{Si}$ is a major element that generally varies less than other major elements [Peplowski et al., 2012a]. For this reason, elemental abundances determined for Mercury have been normalized to Si. First, the abundance of each element was determined using the forward calculation. Then, the element abundance was ratioed to the $\mathrm{Si}$ abundance. Silicon has both inelastic scatter and neutron capture gamma-ray lines that can be analyzed. Other elements, detected by either inelastic scatter or capture mode, can be normalized to the result derived from the corresponding Si mode.

\section{Background Gamma Rays}

[21] As mentioned above, gamma rays are emitted from the spacecraft, material surrounding the detector, and the detector material itself, as well as from the planet. These background sources, except for natural radioactivity, will vary during MESSENGER's orbit around Mercury. Gammaray emission due to activation of spacecraft materials by GCRs varies as one minus the solid angle of Mercury as viewed by the spacecraft. Activation by fast neutrons from Mercury will vary as the solid angle of Mercury. Prompt interactions that produce gamma rays, by fast or thermal neutrons, will also vary as the solid angle of Mercury, though there is a different dependence as the thermal neutrons are gravitationally bound to Mercury. For an analytical description of the altitude dependence of each source of gamma rays, see Peplowski et al. [2012b]. Since many of these background gamma rays are at the same energies as gamma rays from the surface of Mercury, they cannot be characterized by simple peak analysis but must be determined by independent methods. An element that produces gamma rays from both inelastic scatter and neutron capture reactions and for which the signal is dominated by the spacecraft and local materials can be used to estimate the increase in the background for the low-altitude measurements. Orbital XRS measurements indicate that the $\mathrm{Ti}$ abundance on the surface of Mercury is small [Nittler et al., 2011]. The dominant source of measured Ti gamma rays is thus GCR- and planetary-neutron-induced background emission. Therefore, the measured Ti gamma-ray count rates can be used to determine the amplification of the background signals, as a function of altitude, for both inelastic and capture gamma rays. The background amplification factor (ratio of a background signal in the low-altitude sum to that in the highaltitude sum) for inelastic low-energy scatter peaks using the Ti $983 \mathrm{keV}$ peak is equal to $1.49 \pm 0.10$ [Peplowski et al., 2012a] and from the $\mathrm{Ti} 1381 \mathrm{keV}$ capture peak, the value is $\sim 3.7$. The $983 \mathrm{keV}$ peak was analyzed only for the first sidereal day. The first major SPE, on 4 June
2011, produced a long-lived activation product, ${ }^{48} \mathrm{~V}$, which decays with an emission of the same $983 \mathrm{keV}$ gamma ray.

\section{Results}

\subsection{Spatial Coverage}

[22] The standard accumulated spectrum covers three full Mercury sidereal days ( $\sim 177$ Earth days) and represents unbiased coverage of the surface, except for some minor data gaps due to bad flags. The highly eccentric orbit of MESSENGER has a periapsis in the northern hemisphere. The measured gamma-ray spectrum represents the average value over the sampled regions north of $\sim 20^{\circ} \mathrm{S}$. Any measurements acquired for regions south of $\sim 20^{\circ} \mathrm{S}$ were collected at altitudes greater than $2000 \mathrm{~km}$ and were not included in the accumulated low-altitude spectrum. Using measurements from an integral number of sidereal days insures that the measurements are approximately evenly distributed in longitude around Mercury.

\subsection{Elemental Abundances}

\subsubsection{Silicon}

[23] Silicon produces strong gamma rays from both inelastic scatter $(1779 \mathrm{keV})$ and neutron capture $(3539 \mathrm{keV})$ reactions, though normally the capture peaks are much less intense than the inelastic scatter peaks. The relation between the fluxes from inelastic scatter gamma rays and neutron capture gamma rays from the same element depends on the hydrogen content of the materials. With little or no hydrogen expected on Mercury (or in the adopted model), the abundances determined for Si from both mechanisms should give the same result [Evans and Squyres, 1987]. The $\operatorname{Si}\left(\mathrm{n}, \mathrm{n}^{\prime} \gamma\right)$ $1779 \mathrm{keV}$ peak is in a region with a number of other gammaray lines: the fit to this region is shown in Figure 3. The values of the $\mathrm{Si}$ abundance, derived from both the inelastic scatter peak and a capture peak should be the same. Applying the amplification factor from the Ti $983 \mathrm{keV}$ inelastic gamma rays, 1.49 , to the Si inelastic peak and normalizing the $\mathrm{Si}$ capture peak result gives an amplification factor for the capture peak equal to 3.5 , close to the 3.7 value obtained from the Ti capture peak. The peak analysis results for $\mathrm{Si}$ and the other elements discussed below are summarized in Table 2. The uncertainties given in Table 2 for $\mathrm{Si}$ and all other peaks are 1 standard deviation $(\sigma)$ and reflect a combination of statistical uncertainties derived from the peak areas and the background continuum and the goodness of the fit to the measurements.

\subsubsection{Sulfur}

[24] A surprising early result from the MESSENGER XRS orbital measurements was the discovery of abundant sulfur on the surface of Mercury [Nittler et al., 2011]. Sulfur is another element that has measurable gamma rays from both inelastic scatter $(2230 \mathrm{keV})$ and neutron capture (5420 keV plus the first escape peak). The $2230 \mathrm{keV} \mathrm{S}$ peak is Doppler broadened and is part of a region that also contains an Al Doppler-broadened peak $(2211 \mathrm{keV})$, a uranium peak $(2204 \mathrm{keV})$, the hydrogen peak $(2223 \mathrm{keV})$, and the single-escape peak from ${ }^{24} \mathrm{Na}(2243 \mathrm{keV})$. Figure 4 shows the fit to these peaks for both the low- and high-altitude spectra. The presence of a ${ }^{24} \mathrm{Na}$ peak in the spectrum cannot be used directly to measure $\mathrm{Na}$ on the surface, since this activation product can be produced by multiple reactions of 

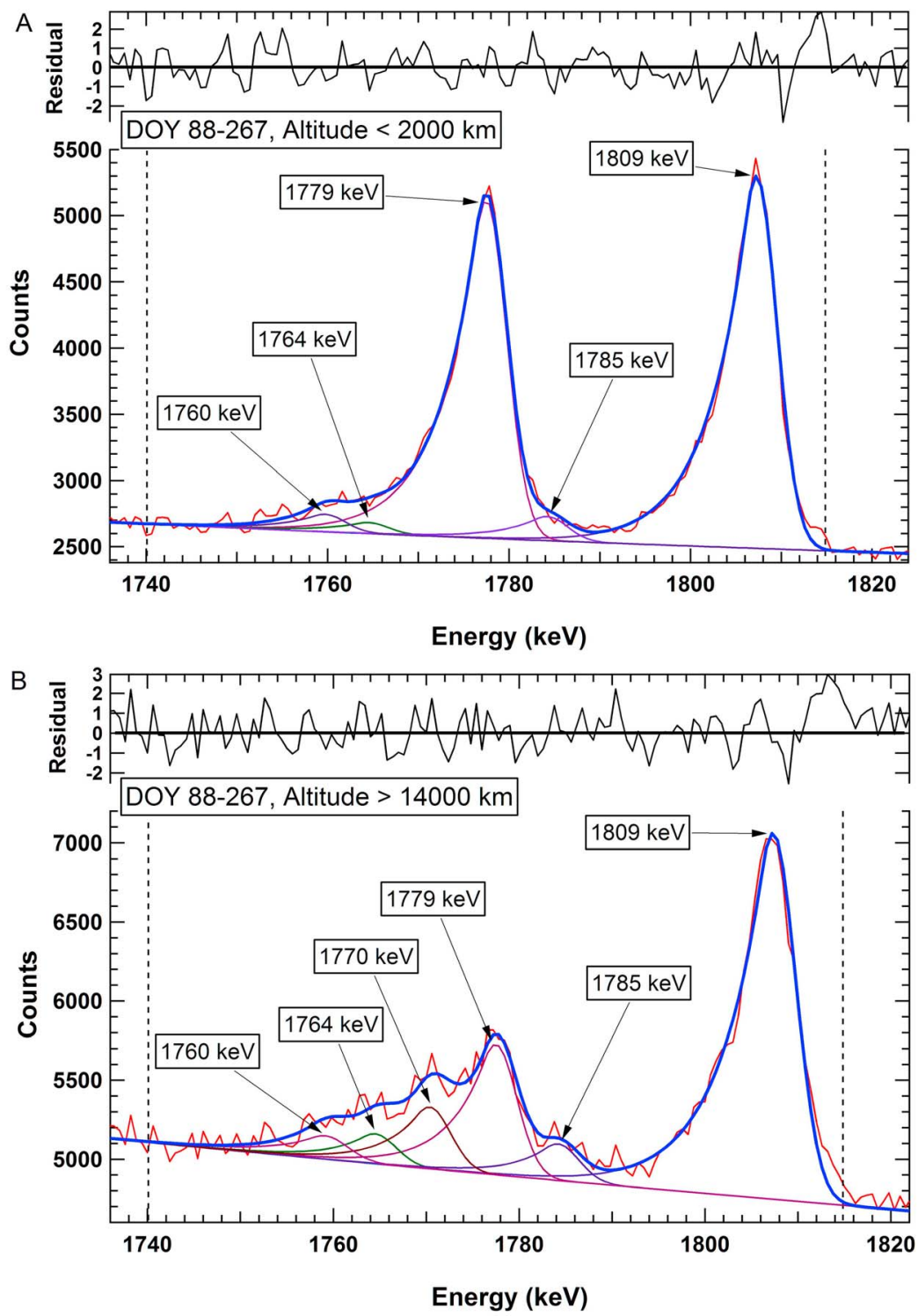

Figure 3. Fit of the $\operatorname{Si}\left(n, n^{\prime} \gamma\right) 1779 \mathrm{keV}$ peak in (a) the low-altitude spectrum and (b) the high-altitude spectrum for the standard spectra accumulated between 29 March 2011 and 24 September 2011 (DOY denotes day of the year). For this and subsequent figures the red curve is the measured spectrum, the various colored curves are the fits to each peak, and the thicker blue curve is the sum of the individual peaks and the fit to the measurements. The vertical black dashed lines denote the limits of the fitting region. The continuum background is fit over a larger region of the spectrum than is shown. The black curve, labeled Residual, is the difference between the fit and the measurements in units of standard deviations, as derived from count statistics. The identifiable peaks in the spectra are $1809 \mathrm{keV}$ from activated ${ }^{26} \mathrm{Mg}, 1785 \mathrm{keV}$ from $\mathrm{Cr}(\mathrm{n}, \gamma)$, and $1764 \mathrm{keV}$ from the decay of ${ }^{238} \mathrm{U}\left({ }^{214} \mathrm{Bi}\right)$.

many common elements (e.g., $\mathrm{Si}, \mathrm{Al}, \mathrm{Mg}$ ). The $\mathrm{H}$ peak analyzed in this region is dominated by neutron interactions in the spacecraft fuel, which obscures any potential hydrogen signal from the planet. As can be seen, this peak is detectable in the high-altitude spectrum and was detected during interplanetary transfer [Goldsten et al., 2007]. The background amplification values derived from Ti for both the inelastic-scatter peak and the capture peak allow the determination of the $\mathrm{S} / \mathrm{Si}$ ratio. The inelastic-scatter gammaray peak gives a $\mathrm{S} / \mathrm{Si}$ ratios of $0.086 \pm 0.017$ and the capture gamma-ray line gives a $\mathrm{S} / \mathrm{Si}$ ratio of $0.11 \pm 0.03$. The two derived $\mathrm{S} / \mathrm{Si}$ values are in excellent agreement, within $1 \sigma$ of each other. The weighted average for these two results is: $\mathrm{S} / \mathrm{Si}=0.090 \pm 0.015$. The abundance results for $\mathrm{S}$ and other elements, relative to $\mathrm{Si}$, are summarized in Table 3, and the weighted averages are summarized in Table 4.

\subsubsection{Calcium}

[25] Calcium has measureable gamma-ray lines from both inelastic scatter $(3736 \mathrm{keV})$ and neutron capture $(1942 \mathrm{keV})$. For $\mathrm{Ca}$, the capture peak has a higher count rate than the inelastic scatter peak. Again, using the background amplification factors from $\mathrm{Ti}$ allows the determination of the $\mathrm{Ca} / \mathrm{Si}$ 
Table 2. Peak Analysis Results ${ }^{\mathrm{a}}$

\begin{tabular}{|c|c|c|c|c|c|c|c|}
\hline \multirow[b]{2}{*}{ Element } & \multirow[b]{2}{*}{ Energy (keV) } & \multicolumn{3}{|c|}{ Low-Altitude } & \multicolumn{3}{|c|}{ High-Altitude } \\
\hline & & Counts & $\mathrm{C} / \mathrm{min}$ & Uncertainty & Counts & $\mathrm{C} / \mathrm{min}$ & Uncertainty \\
\hline $\mathrm{Si}$ & 1779 & 33898 & 2.200 & $0.99 \%$ & 10594 & 0.1966 & $3.71 \%$ \\
\hline $\mathrm{Si}$ & 3539 & 2112.9 & 0.137 & $7.02 \%$ & 195.2 & 0.0036 & $84.2 \%$ \\
\hline $\mathrm{S}$ & 2230 & 2460.5 & 0.160 & $10.9 \%$ & 2192.9 & 0.0407 & $16.0 \%$ \\
\hline $\mathrm{S}$ & 5420 and 4909 & 773.4 & 0.050 & $19.1 \%$ & 45.1 & 0.0008 & $360 \%$ \\
\hline $\mathrm{Ca}$ & 3736 & 628.8 & 0.041 & $24.5 \%$ & 373.9 & 0.0069 & $47.6 \%$ \\
\hline $\mathrm{Ca}$ & 1942 & 2053.9 & 0.133 & $10.9 \%$ & 984.8 & 0.0183 & $30.6 \%$ \\
\hline $\mathrm{Fe}$ & 847 & 4664.5 & 0.739 & $5.55 \%$ & 9789.1 & 0.429 & $3.85 \%$ \\
\hline $\mathrm{Fe}$ & (7632 and 7646) escape peaks & 1037.7 & 0.0673 & $21.1 \%$ & 300.8 & 0.0056 & $220 \%$ \\
\hline $\mathrm{Na}$ & 440 & 56840 & 3.689 & $1.05 \%$ & 151586 & 2.813 & $0.54 \%$ \\
\hline
\end{tabular}

${ }^{\mathrm{a}} \mathrm{C} / \mathrm{min}$ denotes counts per minute. For Fe 847, the analysis spanned days 88 to 147 in 2011 . For Fe 7632 and 7646, the analysis was for the sum of four escape peaks and for altitudes $<1500 \mathrm{~km}$.
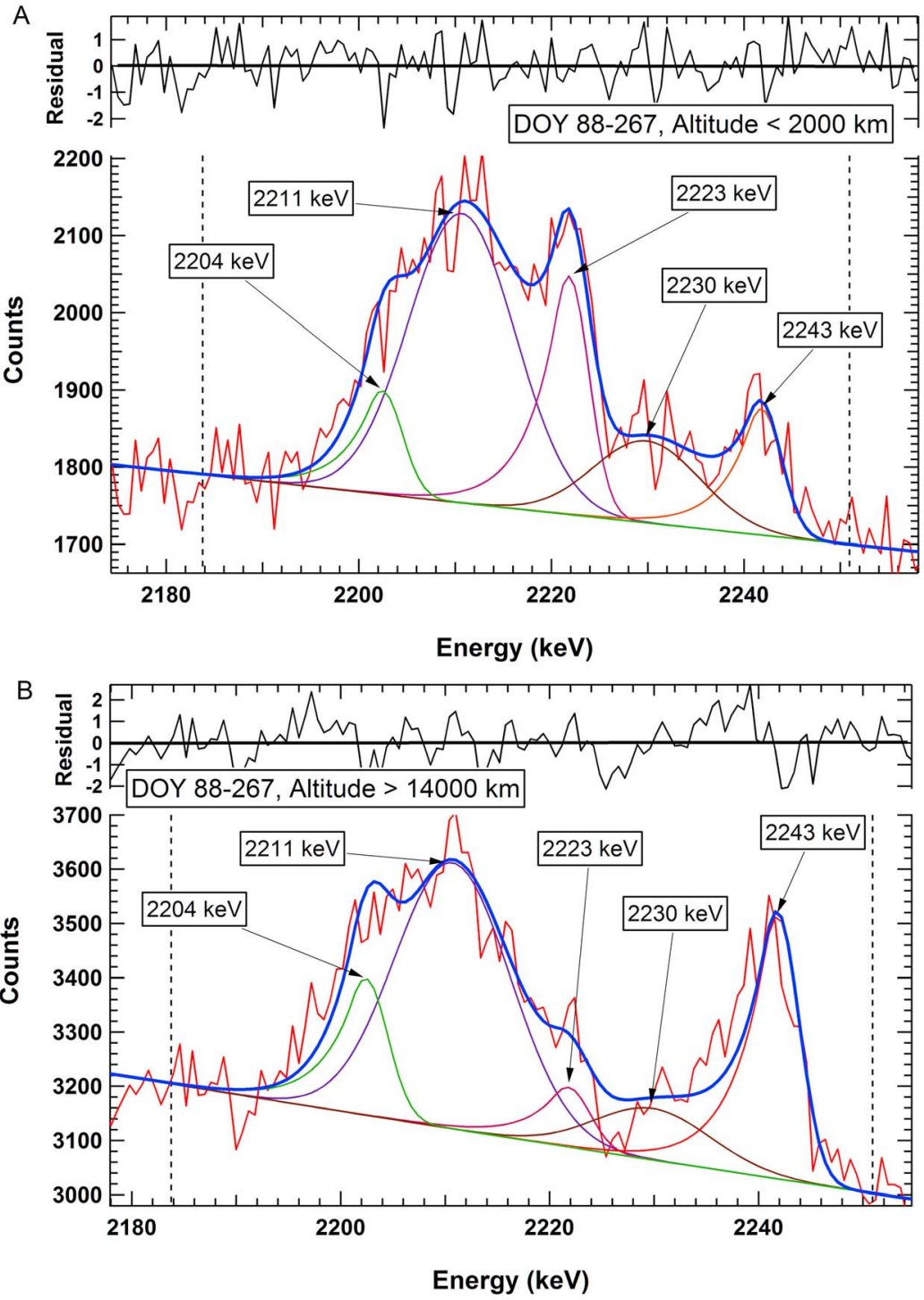

Figure 4. Fit of the $\mathrm{S}\left(\mathrm{n}, \mathrm{n}^{\prime} \gamma\right) 2230 \mathrm{keV}$ Doppler-broadened peak in (a) the low-altitude spectrum and (b) the high-altitude spectrum for the standard spectra accumulated between 29 March 2011 and 24 September 2011. The peaks in the spectra are $\mathrm{Al}\left(\mathrm{n}, \mathrm{n}^{\prime} \gamma\right)$ at $2211 \mathrm{keV}, \mathrm{H}(\mathrm{n}, \gamma)$ at $2223 \mathrm{keV}$, a peak from the decay of ${ }^{238} \mathrm{U}\left({ }^{214} \mathrm{Bi}\right)$ at $2204 \mathrm{keV}$, and the single escape peak of ${ }^{24} \mathrm{Na}$ at $2243 \mathrm{keV}$. 
Table 3. GRS Abundance Ratio Results ${ }^{\mathrm{a}}$

\begin{tabular}{|c|c|c|c|c|c|c|c|c|}
\hline Element & Mode & Energy (keV) & Ratio to $\mathrm{Si}$ & $\sigma$ & Mode & Energy (keV) & Ratio to $\mathrm{Si}$ & $\sigma$ \\
\hline $\mathrm{Ca}$ & $\left(\mathrm{n}, \mathrm{n}^{\prime} \gamma\right)$ & 3736 & 0.28 & 0.10 & $(\mathrm{n}, \gamma)$ & 1942 & 0.22 & 0.06 \\
\hline $\mathrm{S}$ & $\left(\mathrm{n}, \mathrm{n}^{\prime} \gamma\right)$ & 2230 & 0.086 & 0.017 & $(\mathrm{n}, \gamma)$ & 5420 & 0.11 & 0.03 \\
\hline $\mathrm{Fe}$ & $\left(\mathrm{n}, \mathrm{n}^{\prime} \gamma\right)$ & 847 & 0.066 & 0.016 & $(\mathrm{n}, \gamma)$ & (7632 and 7646) & 0.10 & 0.02 \\
\hline $\mathrm{Na}$ & $\left(\mathrm{n}, \mathrm{n}^{\prime} \gamma\right)$ & 440 & 0.12 & 0.01 & & & & \\
\hline $\mathrm{Al}^{\mathrm{b}}$ & $\left(\mathrm{n}, \mathrm{n}^{\prime} \gamma\right)$ & 1114 and 2211 & 0.29 & $+0.05 /-0.13$ & & & & \\
\hline
\end{tabular}

${ }^{\text {a }}$ Radios are by weight, $\sigma$ denotes one standard deviation.

${ }^{\mathrm{b}} \mathrm{Al}$ results are from Peplowski et al. [2012b].

ratio as $0.28 \pm 0.10$ and $0.22 \pm 0.06$ for the inelastic scatter gamma ray and capture gamma ray, respectively. As for $\mathrm{S} / \mathrm{Si}$, the two values are within $1 \sigma$ of each other, and a weighted average for these two results gives $\mathrm{Ca} / \mathrm{Si}=0.24 \pm 0.05$.

\subsubsection{Sodium}

[26] Sodium is an important rock-forming element long known to be present in the weak exosphere surrounding Mercury [Potter and Morgan, 1985; Sprague et al., 1998]. Unlike $\mathrm{Ca}$ and $\mathrm{S}, \mathrm{Na}$ is not measureable by the MESSENGER XRS. It has gamma rays from both inelastic scatter $(440 \mathrm{keV})$ and neutron capture $(472 \mathrm{keV})$. However, both of these gamma rays are subject to interferences from other gamma rays at similar energies; from activation of ${ }^{69 m} \mathrm{Zn}$ (where the symbol $m$ denotes a metastable state) at $439 \mathrm{keV}$ and from ${ }^{10} \mathrm{~B}$ at $478 \mathrm{keV}$ [Evans et al., 2006]. The ${ }^{10} \mathrm{~B}$ background arises from neutron capture within the borated plastic anticoincidence shield. This neutron capture is followed by the emission of an alpha particle to make excited ${ }^{7} \mathrm{Li}$, and the peak has a unique broadened flat-top shape that interferes with the $\mathrm{Na}$ capture peak, so the latter cannot be used to derive a $\mathrm{Na}$ abundance. The ${ }^{69 \mathrm{~m}} \mathrm{Zn}$ is a spallation product of GCRs interacting with the detector material. It was detected early in the interplanetary cruise measurements and in each of the preflyby measurements [Goldsten et al., 2007]. The gamma-ray background count rate from ${ }^{69 \mathrm{~m}} \mathrm{Zn}$ (half-life of $13 \mathrm{~h}$ ) can be considered constant over the orbital period of MESSENGER as the GCR excitation source can be regarded as constant through most of the orbit. The background from $\mathrm{Na}$ on the spacecraft is negligible compared with the ${ }^{69 \mathrm{~m}} \mathrm{Zn}$ contribution. The abundance of $\mathrm{Na}$ can be determined directly by subtracting the high-altitude measurement of the $440 \mathrm{keV}$ inelastic peak from the low-altitude measurement. The fits for the low-altitude and high-altitude spectra are shown in Figure 5. This procedure gives an abundance ratio for $\mathrm{Na} / \mathrm{Si}$ of $0.12 \pm 0.01$. As a check on the assumption of a constant background, spectra were accumulated for lowaltitude cutoffs of $1500 \mathrm{~km}$ and $1000 \mathrm{~km}$. Analysis of these spectra along with the corresponding forward calculation gave identical results, within the statistical uncertainties. The strong
Na signal offers the potential for achieving some spatial resolution that has so far been possible only for gamma-ray measurements of K and Si [Peplowski et al., 2012a].

\subsubsection{Iron}

[27] Iron has gamma rays from both inelastic scatter (e.g., $847 \mathrm{keV}$ ) and from neutron capture (e.g., a doublet at 7632 and $7646 \mathrm{keV}$ ). However, both the inelastic and capture peaks are difficult to analyze. As mentioned above, the $\mathrm{Fe}\left(\mathrm{n}, \mathrm{n}^{\prime} \gamma\right)$ peak at $847 \mathrm{keV}$ was contaminated by the production of ${ }^{56} \mathrm{Co}$ (half-life of 77 days) caused by an SPE that occurred on 4 June 2011. Thus the analysis was limited to a spectrum accumulated over a period of 59 days instead of the 177 days used for the analysis of the other elements. The $\mathrm{Fe}\left(\mathrm{n}, \mathrm{n}^{\prime} \gamma\right) 847 \mathrm{keV}$ peak is in a region that includes a sawtooth peak from fast neutron interactions in the $\mathrm{Ge}$ detector, and the fit for this region is shown in Figure 6. The $\mathrm{Fe}(\mathrm{n}, \gamma)$ doublet at $7632 \mathrm{keV}$ and $7646 \mathrm{keV}$ has the highest flux of any iron capture gamma ray, but because of the high energy of these gamma rays and the small volume of the detector, the detection efficiency is small. However, the escape peaks for these gamma rays have greater detection efficiencies than the corresponding full energy peaks [Goldsten et al., 2007]. Calibration measurements were made with radioactive sources with energies up to $6 \mathrm{MeV}$; at higher energies, calculations were used to estimate escape peak efficiencies.

[28] No peaks from the capture gamma rays from iron were detectable in the standard low-altitude spectrum. However, when a low-altitude spectrum with a $1500 \mathrm{~km}$ threshold was used, both the single-escape and doubleescape peaks from this doublet, i.e., a total of four peaks, could be analyzed. Analysis of the inelastic scatter peak gives an $\mathrm{Fe} / \mathrm{Si}$ ratio of $0.066 \pm 0.016$, whereas the $\mathrm{Fe} / \mathrm{Si}$ ratio derived from a sum of the four individual neutron capture escape peaks is $0.10 \pm 0.02$. The weighted average for these two results is $\mathrm{Fe} / \mathrm{Si}=0.077 \pm 0.013$.

\subsubsection{Aluminum}

[29] The analysis of two Al inelastic scatter peaks at different energies (1014 keV and $2211 \mathrm{keV})$ described by

Table 4. Absolute Abundances and Abundance Ratios

\begin{tabular}{|c|c|c|c|c|c|}
\hline Element Ratio $^{\mathrm{a}}$ & Weighted Average & Weighted $\sigma$ & Element & Abundance wt $\%$ & $\sigma \mathrm{wt} \%$ \\
\hline & & & $\mathrm{Si}$ & $24.6^{\mathrm{b}}$ & \\
\hline $\mathrm{Ca} / \mathrm{Si}$ & 0.24 & 0.05 & $\mathrm{Ca}$ & 5.9 & 1.3 \\
\hline $\mathrm{S} / \mathrm{Si}$ & 0.092 & 0.015 & $\mathrm{~S}$ & 2.3 & 0.4 \\
\hline $\mathrm{Fe} / \mathrm{Si}$ & 0.077 & 0.013 & $\mathrm{Fe}$ & 1.9 & 0.3 \\
\hline \multirow[t]{2}{*}{$\mathrm{Na} / \mathrm{Si}$} & 0.12 & 0.01 & $\mathrm{Na}$ & 2.9 & 0.1 \\
\hline & & & $\mathrm{Al}^{\mathrm{c}}$ & 7.1 & $+0.4 /-0.9$ \\
\hline
\end{tabular}

\footnotetext{
${ }^{\mathrm{a}}$ Ratios are by weight.

${ }^{\mathrm{b}}$ Assumed from bulk composition model.

${ }^{\mathrm{c}}$ From Peplowski et al. [2012b].
} 

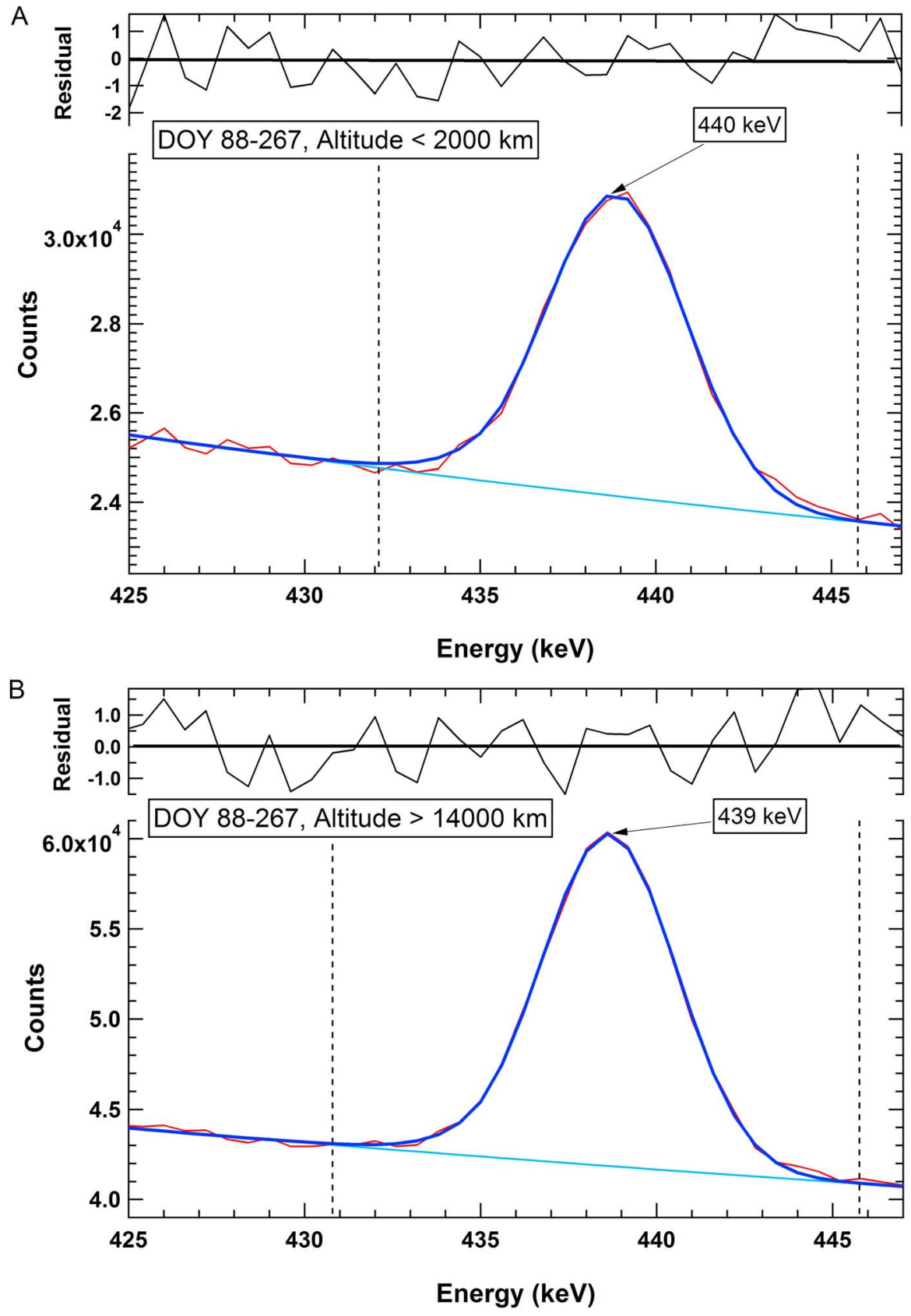

Figure 5. Fit of the $\mathrm{Na}\left(\mathrm{n}, \mathrm{n}^{\prime} \gamma\right) 440 \mathrm{keV}$ peak in (a) the low-altitude spectrum and (b) the high-altitude spectrum for the standard spectra accumulated between 29 March 2011 and 24 September 2011. The $439 \mathrm{keV}$ label on the high-altitude fit corresponds to the ${ }^{69 \mathrm{~m}} \mathrm{Zn}$ peak, though the energy resolution is not sufficient to distinguish between that and the $440 \mathrm{keV}$ peak.

Peplowski et al. [2012b] gives an Al/Si ratio of $0.29(+0.05$, $-0.13)$, consistent with the XRS results of Nittler et al. [2011] and Weider et al. [2012].

\subsubsection{Other Elements}

[30] Of the major rock-forming elements that could be analyzed from the GRS measurements, only oxygen is not reported here. The GRS derived $\mathrm{O} / \mathrm{Si}$ abundance ratio was $1.40( \pm 0.03)$, about $20 \%$ lower than that from the model abundances (1.72) and lower than any measured meteorite values as compiled by Nittler et al. [2004]. Comparison of the forward model prediction for $\mathrm{O}$ to previous gamma-ray calculations [Masarik and Reedy, 1996; Brückner and Masarik, 1997] indicates that these calculated count rates are higher than expected for the assumed $\mathrm{O}$ abundance. The Mars surface $\mathrm{O}$ abundance was not determined by the Mars Odyssey GRS because of interference from the largely $\mathrm{CO}_{2}$ atmosphere. Since the forward calculation for $\mathrm{O}$ was not validated during the Mars Odyssey mission, as for the other elements, there is no validation for accuracy of the adopted $\mathrm{O}$ cross sections and results, so we do not report an $\mathrm{O}$ abundance here. 

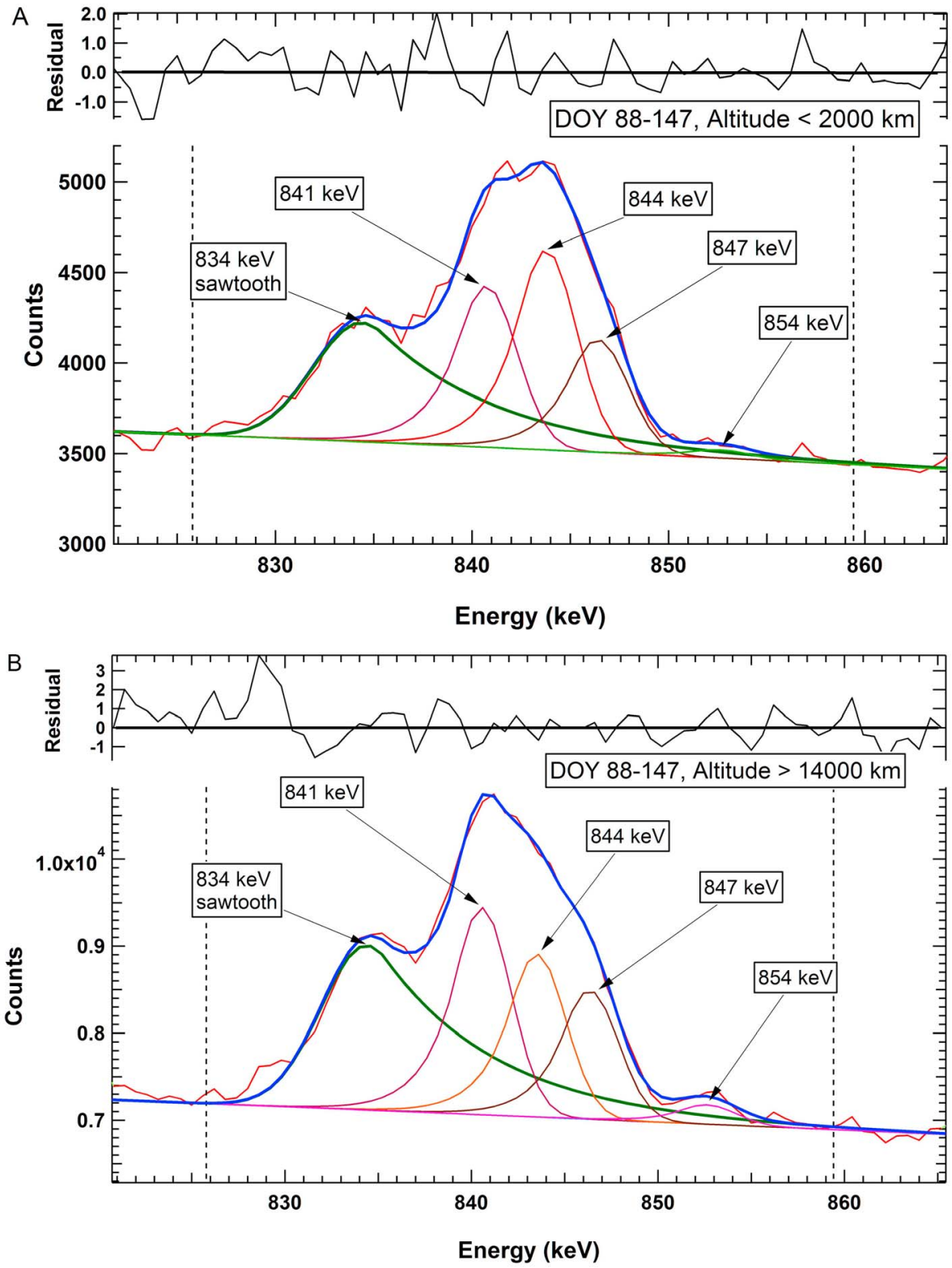

Figure 6. Fit of the $\mathrm{Fe}\left(\mathrm{n}, \mathrm{n}^{\prime} \gamma\right) 847 \mathrm{keV}$ peak in (a) the low-altitude spectrum and (b) the high-altitude spectrum for the spectra accumulated between 29 March 2011 and 27 May 2011. The curve labeled $834 \mathrm{keV}$ sawtooth is due to fast neutrons interacting in the detector material. The other peaks in the spectra are from the decay of ${ }^{54} \mathrm{Mn}$, and possibly some $\mathrm{S}(\mathrm{n}, \gamma)$, at $841 \mathrm{keV}$, from $\mathrm{Al}\left(\mathrm{n}, \mathrm{n}^{\prime} \gamma\right)$ at $844 \mathrm{keV}$, and from the decay of ${ }^{56} \mathrm{Co}$ at $854 \mathrm{keV}$.

[31] There are other elements included in the forward model composition (Table 1) that have large neutron capture cross sections and relatively strong gamma rays (e.g., $\mathrm{Cl}, \mathrm{Cr}$, and $\mathrm{Mn}$ ) that were not detected in the standard summed spectrum. One of the limitations for detection is the low detector efficiency of the GRS for high-energy gamma rays, e.g., $\mathrm{Cr}$ at $8884 \mathrm{keV}$ and $\mathrm{Mn}$ at $7243 \mathrm{keV}$. Measurements continued over the duration of the primary mission as well as into the extended mission (up to an additional Earth year) may allow the detection or firm upper limits to be placed on the abundance of elements that were not detected during the primary mission. The detection of the $\mathrm{H}$ peak in the 2204-2243 keV region (Figure 4) is from the fuel on the spacecraft. As the mission evolves, the remaining fuel will decrease, and a point may be reached later in the mission at which measurement of $\mathrm{H}$ is possible.

\section{Discussion}

\subsection{Abundances Calculated for an Assumed Si Abundance}

[32 ] Converting elemental ratios (normalized to $\mathrm{Si}$ ) to absolute abundances requires knowledge of the absolute $\mathrm{Si}$ abundance. Nittler et al. [2011] used ratios of XRS-derived major elements to silicon to estimate a bulk Si abundance for Mercury of $\sim 25 \mathrm{wt} \%$, under the assumption of normal 
Table 5. Comparison With XRS Results ${ }^{\mathrm{a}}$

\begin{tabular}{|c|c|c|c|c|c|c|}
\hline \multirow[b]{2}{*}{ Ratio } & \multicolumn{2}{|c|}{ GRS Results } & \multirow[b]{2}{*}{ Region } & \multicolumn{3}{|c|}{ XRS Results } \\
\hline & Mean & $\sigma$ & & Mean & $\mathrm{SD}$ & Median \\
\hline \multirow[t]{2}{*}{$\mathrm{Al} / \mathrm{Si}$} & 0.29 & $+0.05 /-0.13$ & IcP-HCT & 0.22 & 0.08 & 0.23 \\
\hline & & & NP & 0.26 & 0.07 & 0.26 \\
\hline \multirow[t]{2}{*}{$\mathrm{S} / \mathrm{Si}$} & 0.09 & 0.02 & IcP-HCT & 0.09 & 0.03 & 0.09 \\
\hline & & & NP & 0.06 & 0.02 & 0.06 \\
\hline \multirow[t]{2}{*}{$\mathrm{Ca} / \mathrm{Si}$} & 0.24 & 0.05 & IcP-HCT & 0.19 & 0.04 & 0.19 \\
\hline & & & NP & 0.15 & 0.04 & 0.16 \\
\hline
\end{tabular}

${ }^{\mathrm{a}} \mathrm{Al}$ results are from Peplowski et al. [2012b]. IcP-HCT denotes intercrater plains and heavily cratered terrain. NP denotes volcanic northern plains. XRS results are from Weider et al. [2012], SD is the standard deviation of multiple measurements.

stoichiometry for oxides of major cations in order to estimate the $\mathrm{O}$ abundance followed by normalization of the total composition to $100 \%$. This Si abundance is similar to that of the partially melted enstatite chondrite composition of Burbine et al. [2002], $25.7 \mathrm{wt} \%$, which is also similar to that derived from petrologic modeling of representative Mercury crustal compositions (K. R. Stockstill-Cahill et al., Magnesiumrich crustal compositions on Mercury: Implications for magmatism from petrologic modeling, submitted to Journal of Geophysical Research, 2012), $24.3 \mathrm{wt} \%$. The value used here for the forward modeling (Table 1) of $24.6 \mathrm{wt} \%$ is thus in line with other estimates and is appropriate to derive absolute abundances for the other elements measured by GRS (Table 4).

\subsection{Comparison With the Assumed Forward Model Composition}

[33] As discussed above, the bulk composition can affect the thermal neutron spatial distribution and, as a result, the measured neutron capture fluxes. High concentrations of elements with large cross sections for the removal of thermal and epithermal neutrons decrease the flux of neutron capture gamma rays. The model composition used for the forward calculation was based on expected abundances from other sources and measurements. The low value of $\mathrm{Fe}$ and the nondetection of $\mathrm{Ti}, \mathrm{Mn}$, and rare earth elements (e.g., Gd, $\mathrm{Sm})$ are consistent with the assumed macroscopic cross section and average atomic mass and validates the abundances assumed in the forward model (Table 1). Although this model solution is not unique, Boynton et al. [2007] showed that small variations in these elemental abundances will not change the results.

\subsection{Comparison With GRS Flyby Measurements}

[34] During the MESSENGER flybys of Mercury, the GRS made measurements of gamma rays from the near-equatorial region. Despite being limited by the low planetary fluxes, sufficient counts were accumulated to estimate abundances for some elements with relatively strong gamma-ray peaks, including $\mathrm{Si}, \mathrm{Fe}, \mathrm{Ti}, \mathrm{K}$, and $\mathrm{Th}$ [Rhodes et al., 2011]. Absolute abundances for the radioactive elements $\mathrm{K}$, Th, and $\mathrm{U}$ obtained from early orbital measurements have been described by Peplowski et al. [2011b]. Orbital measurements have also been used to examine the spatial heterogeneity of the radioactive elements $\mathrm{K}$ and $\mathrm{Th}$ by Peplowski et al. [2012a]. Analysis of the GRS flyby results for Fe gave an $\mathrm{Fe} / \mathrm{Si}$ ratio of $0.27 \pm 0.14$, higher than, but within $2 \sigma$ of the orbital results. This comparison suggests that there is not a strong latitudinal dependence of the $\mathrm{Fe} / \mathrm{Si}$ abundance, but this inference should be tempered by the large uncertainties in the flyby measurements. Although Ti was not detected unambiguously in the flyby measurements, its derived abundance of $1.2 \pm 2.9 \mathrm{wt} \%$ is consistent with the orbital XRS measurements [Nittler et al., 2011] indicating an abundance of $<1 \mathrm{wt} \%$. The analysis of the orbital GRS measurements of the Ti inelastic scatter line at $983 \mathrm{keV}$ showed that adopting the same value for the background amplification factor as that used for the flybys gives an unphysical negative Ti abundance [see Peplowski et al., 2012b]. For these reasons, Ti was used to determine the background amplification factors for the orbital analysis.

\subsection{Comparison With XRS Results}

[35] The XRS on MESSENGER measures elemental composition by detection of X-rays emitted through the interaction of solar-generated X-rays with surface materials. There are two major differences between the GRS and XRS measurements. First, XRS is sensitive to the top tens of micrometers of the surface, compared with tens of centimeters for GRS. Second, the XRS is collimated, limiting the field of view (FOV) to $12^{\circ}$. This FOV provides relatively high spatial resolution in the northern hemisphere (down to $<100 \mathrm{~km}$ ) when the spacecraft is close to the planet and lower spatial resolution in the southern hemisphere when the spacecraft is at higher altitudes. Four major-element ratios can be measured by both XRS and GRS: $\mathrm{Al} / \mathrm{Si}, \mathrm{S} / \mathrm{Si}, \mathrm{Ca} / \mathrm{Si}$, and $\mathrm{Fe} / \mathrm{Si}$ [Nittler et al., 2011; Weider et al., 2012]. Weider et al. [2012] presented spatially resolved measurements of $\mathrm{Mg} / \mathrm{Si}, \mathrm{Al} / \mathrm{Si}, \mathrm{S} / \mathrm{Si}$, and $\mathrm{Ca} / \mathrm{Si}$ for a number of regions in the northern hemisphere that broadly encompass the large expanse of northern volcanic plains [Head et al., 2011] as well as the surrounding mix of intercrater plains and heavily cratered terrain. These terrains also correspond to the two most common geological terrain types sampled by the GRS measurements, and the data can thus be compared. Table 5 summarizes the elemental ratio values that GRS and XRS have in common.

[36] The MESSENGER XRS also measures Fe, but only during solar flares sufficiently energetic to cause the fluorescence of Fe X-rays. The results reported by Nittler et al. [2011] for the strongest solar flares gave an Fe/Si ratio in the range $0.01-0.15$, all for areas at near-equatorial or southern latitudes on Mercury. Because of the different regions sampled, the relatively few XRS Fe measurements, and the fact that the XRS Fe analysis is more susceptible to systematic errors than that for the other reported elements, it is difficult to compare directly the GRS and XRS results for iron. Nonetheless, the GRS Fe/Si value is within the range reported for the XRS values, confirming the overall low abundance of $\mathrm{Fe}$ at Mercury's surface.

\subsection{Comparison With Ground-Based Observations of Mercury's Surface and Exosphere}

[37] As described above, the forward modeling of the GRS data has been conducted for a $\mathrm{Si}$ abundance of $24.6 \mathrm{wt} \%$, consistent with estimates from major-element abundances reported from analysis of XRS measurements [Nittler et al., 2011; Weider et al., 2012]. This value is also consistent with estimates derived from the location of the transmission 
minimum seen in midinfrared spectra of Mercury's surface obtained with ground-based telescope observations [Sprague et al., 2007].

[38] The GRS results, along with the elemental abundances measured by the XRS, have clarified results from groundbased spectroscopy and multispectral imaging of Mercury's surface and composition. One of the most important findings is the confirmation of low total iron on Mercury's surface. Neither Earth-based [Vilas, 1988; Blewett et al., 2002] nor MESSENGER-derived [McClintock et al., 2008; Robinson et al., 2008; Denevi et al., 2009] reflectance spectra of Mercury display a $1 \mu \mathrm{m}$ absorption feature associated with ferrous iron in silicates, limiting $\mathrm{FeO}$ in the silicates at Mercury's surface to less than 2-3\% [Vilas, 1988; Blewett et al., 2009; Riner et al., 2010]. Thermal emission spectra in the midinfrared also suggest the presence of $\mathrm{MgO}$-rich orthopyroxene and olivine, with the total $\mathrm{FeO}$ abundance in the range from 2-5\% [Sprague et al., 2009]. The inference of MgO-rich mafic silicates is also consistent with relatively high $\mathrm{Mg} / \mathrm{Si}$ ratios found by the MESSENGER XRS [Nittler et al., 2011; Weider et al., 2012]. Ground-based observations have found a spectral feature near $5 \mu \mathrm{m}$ indicative of clinopyroxene high in $\mathrm{Ca}$ and $\mathrm{Mg}$ (e.g., $\mathrm{CaMgSi}_{2} \mathrm{O}_{6}$ ) in some plains regions [Strom and Sprague, 2003]. However, the XRS results [Nittler et al., 2011; Weider et al., 2012] indicate that, on the whole, Mercury has a low $\mathrm{Ca} / \mathrm{Si}$ ratio, which is borne out by the absence of clinopyroxene in petrologic models for Mercury surface materials (StockstillCahill et al., submitted manuscript, 2012). The GRS and XRS results are consistent with $\mathrm{Mg}$-rich and low-Ca silicates.

[39] The relatively high $\mathrm{Na}$ abundance reported here (compared with that expected from the model abundance in Table 1) is consistent with evidence for Na-bearing plagioclase feldspar inferred from ground-based spectral measurements. Several measurements described by Sprague et al. [2007] are consistent with feldspar compositions ranging from albite $\left(\mathrm{NaAlSi}_{3} \mathrm{O}_{8}\right)$, with up to $5 \mathrm{wt} \%$ anorthite $\left(\mathrm{CaAl}_{2} \mathrm{Si}_{2} \mathrm{O}_{8}\right)$, to labradorite with $30-50 \mathrm{wt} \%$ albite. Thus, $\mathrm{Na}$-bearing plagioclase may account for much of the $\mathrm{Na}$ measured by the GRS. A high-energy distribution of $\mathrm{Ca}$ in the exosphere [Vervack et al., 2010] has been modeled by M. H. Burger et al. (Modeling MESSENGER observations of calcium in Mercury's exosphere: Flyby observations, submitted to Journal of Geophysical Research, 2012) and found to suggest a dawnside source region that does not appear to be associated with any specific geologic region. A likely source is sputtering from Ca-bearing plagioclase, but other possibilities are CaS [Nittler et al., 2011; Weider et al., 2012] and MgO-rich, low-Ca clinopyroxene, both of which are consistent with a relatively albitic plagioclase component. In order to relate directly the $\mathrm{Na}$ and $\mathrm{K}$ measured in the exosphere with the GRS results, it may be helpful to map the $\mathrm{Na}$ abundance distribution on Mercury as has been done for the $\mathrm{K}$ abundance [Peplowski et al., 2012a].

\section{Conclusions}

[40] Analysis of the MESSENGER orbital GRS measurements has yielded the abundances of several major elements on Mercury: $\mathrm{Al}, \mathrm{Ca}, \mathrm{S}, \mathrm{Fe}$, and $\mathrm{Na}$. For those elements that have been measured by both GRS and XRS (Al, Ca, S, Fe), there are no appreciable differences in the derived abundances. This agreement indicates that Mercury's regolith is, on average, vertically homogeneous to a depth of tens of centimeters. The GRS results confirm the low total Fe abundance on Mercury's surface previously inferred from spectral reflectance and XRS measurements. The GRS and XRS elemental results are most consistent with petrologic models suggesting that Mercury's surface is dominated by Mg-rich silicates. The observed $\mathrm{Na}$ abundance of $\sim 3 \%$ suggests that plagioclase feldspar on Mercury's surface is relatively rich in albite. The derivation of $\mathrm{Na}$ maps may help to constrain source processes for the $\mathrm{Na}$ in Mercury's exosphere.

[41] Acknowledgments. We thank the entire MESSENGER team for their invaluable contributions to the development and operation of the MESSENGER spacecraft. This work was supported in part by the MESSENGER Participating Scientist program under contract NNH08CC06C to Computer Sciences Corporation. The MESSENGER project is supported by the NASA Discovery Program under contract NAS5-97271 to The Johns Hopkins University Applied Physics Laboratory and NASW-00002 to the Carnegie Institution of Washington. We also thank two anonymous reviewers for their thoughtful suggestions to improve this paper.

\section{References}

Blewett, D. T., B. R. Hawke, and P. G. Lucey (2002), Lunar pure anorthosite as a spectral analog for Mercury, Meteorit. Planet. Sci., 37, 1245-1254, doi:10.1111/j.1945-5100.2002.tb00893.x.

Blewett, D. T., M. S. Robinson, B. W. Denevi, J. J. Gillis-Davis, J. W. Head, S. C. Solomon, G. M. Holsclaw, and W. E. McClintock (2009), Multispectral images of Mercury from the first MESSENGER flyby: Analysis of global and regional color trends, Earth Planet. Sci. Lett., 285, 272-282, doi:10.1016/j.epsl.2009.02.021.

Boynton, W. V., et al. (2007), Concentration of H, Si, Cl, K, Fe, and Th in the low- and mid-latitude regions of Mars, J. Geophys. Res., 112, E12S99, doi:10.1029/2007JE002887.

Brückner, J., and J. Masarik (1997), Planetary gamma-ray spectoscopy of the surface of Mercury, Planet. Space Sci., 45, 39-48, doi:10.1016/ S0032-0633(96)00093-1.

Brückner, J., M. Koerfer, H. Wänke, A. N. F. Schroeder, D. Filges, P. Dragovitsch, P. A. J. Englert, R. Starr, and J. I. Trombka (1991), Proton-induced radiation damage in germanium detectors, IEEE Trans. Nucl. Sci., 38, 209-217, doi:10.1109/23.289298.

Burbine, T. H., T. J. McCoy, L. R. Nittler, G. K. Benedix, E. A. Cloutis, and T. L. Dickinson (2002), Spectra of extremely reduced assemblages: Implications for Mercury, Meteorit. Planet. Sci., 37, 1233-1244, doi:10.1111/ j.1945-5100.2002.tb00892.x.

Denevi, B. W., et al. (2009), The evolution of Mercury's crust: A global perspective from MESSENGER, Science, 324, 613-618, doi:10.1126/ science. 1172226

Evans, L. G., and S. W. Squyres (1987), Investigation of Martian $\mathrm{H}_{2} \mathrm{O}$ and $\mathrm{CO}_{2}$ via orbital gamma ray spectroscopy, J. Geophys. Res., 92, 9153-9167, doi:10.1029/JB092iB09p09153.

Evans, L. G., R. C. Reedy, and J. I. Trombka (1993), Introduction to planetary remote sensing gamma-ray spectroscopy, in Remote Geochemical Analyses: Elemental and Mineralogical Composition, edited by C. M. Peters and P. A. J. Englert, pp. 167-198, Cambridge Univ. Press, New York.

Evans, L. G., R. C. Reedy, R. D. Starr, K. E. Kerry, and W. V. Boynton (2006), Analysis of gamma ray spectra measured by Mars Odyssey, J. Geophys. Res., 111, E03S04, doi:10.1029/2005JE002657.

Feldman, W. C., D. J. Lawrence, R. C. Elphic, D. T. Vaniman, D. R. Thomsen, B. L. Barraclough, S. Maurice, and A. B. Binder (2000), Chemical information content of lunar thermal and epithermal neutrons, J. Geophys. Res., 105, 20,347-20,363, doi:10.1029/1999JE001183.

Gasnault, O., W. C. Feldman, S. Maurice, I. Genetay, C. d'Uston, T. H. Prettyman, and K. R. Moore (2001), Composition from fast neutrons: Application to the Moon, Geophys. Res. Lett., 28, 3797-3800, doi:10.1029/2001GL013072.

Goldsten, J. O., et al. (2007), The MESSENGER Gamma-Ray and Neutron Spectrometer, Space Sci. Rev., 131, 339-391, doi:10.1007/s11214-0079262-7.

Head, J. W., et al. (2011), Flood volcanism in the northern high latitudes of Mercury revealed by MESSENGER, Science, 333, 1853-1856, doi:10.1126/science. 1211997. 
Kim, K. J., D. M. Drake, R. C. Reedy, R. M. S. Williams, and W. V. Boynton (2006), Theoretical fluxes of gamma rays from the Martian surface, J. Geophys. Res., 111, E03S09, doi:10.1029/2005JE002655 [printed 112(E3), 2007]

Lawrence, D. J., W. C. Feldman, J. O. Goldsten, T. J. McCoy, D. T. Blewett, W. V. Boynton, L. G. Evans, L. R. Nittler, E. A. Rhodes, and S. C. Solomon (2010), Identification and measurement of neutron-absorbing elements on Mercury's surface, Icarus, 209, 195-209, doi:10.1016/ j.icarus.2010.04.005.

Masarik, J., and R. C. Reedy (1996), Gamma ray production and transport in Mars, J. Geophys. Res., 101, 18,891-18,912, doi:10.1029/96JE01563.

McAdams, J. V., R. W. Farquhar, A. H. Taylor, and B. G. Williams (2007), MESSENGER mission design and navigation, Space Sci. Rev., 131, 219-246, doi:10.1007/s11214-007-9162-x.

McClintock, W. E., et al. (2008), Spectroscopic observations of Mercury's surface reflectance during MESSENGER's first Mercury flyby, Science, 321, 62-65, doi:10.1126/science.1159933.

McKinney, G. W., D. J. Lawrence, T. H. Prettyman, R. C. Elphic, W. C. Feldman, and J. J. Hagerty (2006), MCNPX benchmark for cosmic ray interactions with the Moon, J. Geophys. Res., 111, E06004, doi:10.1029/ 2005JE002551.

Nittler, L. R., T. J. McCoy, P. E. Clark, M. E. Murphy, J. I. Trombka, and E. Jarosewich (2004), Bulk element compositions of meteorites: A guide for interpreting remote-sensing geochemical measurements of planets and asteroids, Antarct. Meteorite Res., 17, 233-253.

Nittler, L. R., et al. (2011), The major element composition of Mercury's surface from MESSENGER X-ray spectrometry, Science, 333, 1847-1850, doi:10.1126/science. 1211567.

Peplowski, P. N., D. T. Blewett, B. W. Denevi, L. G. Evans, D. J. Lawrence, L. R. Nittler, E. A. Rhodes, C. M. Selby, and S. C. Solomon (2011a), Mapping iron abundances on the surface of Mercury: Predicted spatial resolution of the MESSENGER Gamma-Ray Spectrometer, Planet. Space Sci., 59, 1654-1658, doi:10.1016/j.pss.2011.06.001.

Peplowski, P. N., et al. (2011b), Radioactive elements on Mercury's surface from MESSENGER: Implications for the planet's formation and evolution, Science, 333, 1850-1852, doi:10.1126/science.1211576.

Peplowski, P. N., et al. (2012a), Variations in the abundances of potassium and thorium on the surface of Mercury: Results from the MESSENGER Gamma-Ray Spectrometer, J. Geophys. Res., 117, E00L04, doi:10.1029/ 2012JE004141.

Peplowski, P. N., E. A. Rhodes, D. K. Hamara, D. J. Lawrence, L. G. Evans, L. R. Nittler, and S. C. Solomon (2012b), Aluminum abundance on the surface of Mercury: Application of a new background-reduction technique for the analysis of gamma-ray spectroscopy data, J. Geophys. Res., doi:10.1029/2012JE004181, in press.
Potter, A. E., and T. H. Morgan (1985), Discovery of sodium in the atmosphere of Mercury, Science, 229, 651-653, doi:10.1126/science.229. 4714.651.

Rhodes, E. A., et al. (2011), Analysis of MESSENGER Gamma-Ray Spectrometer data from the Mercury flybys, Planet. Space Sci., 59, 1829-1841, doi:10.1016/j.pss.2011.07.018.

Riner, M. A., F. M. McCubbin, G. J. Taylor, and J. J. Gillis-Davis (2010) Mercury surface composition: Integrating petrologic modeling and remote sensing data to place constraints on $\mathrm{FeO}$ abundance, Icarus, 209 , 301-313, doi:10.1016/j.icarus.2010.05.018.

Robinson, M. S., S. L. Murchie, D. T. Blewett, D. L. Domingue, S. E. Hawkins, J. W. Head, G. M. Holsclaw, W. E. McClintock, S. C. Solomon, and T. R. Watters (2008), Reflectance and color variations on Mercury: Regolith processes and compositional heterogeneity, Science, 321, 66-69, doi:10.1126/science.1160080.

Solomon, S. C., R. L. McNutt Jr., R. E. Gold, and D. L. Domingue (2007), MESSENGER mission overview, Space Sci. Rev., 131, 3-39, doi:10.1007/ s11214-007-9247-6.

Sprague, A. L., W. J. Schmitt, and R. E. Hill (1998), Sodium atmospheric enhancements, radar bright spots, and visible surface features, Icarus, 136 , 60-68, doi:10.1006/icar.1998.6009.

Sprague, A. L., A. J. Warell, G. Cremonese, Y. Langevin, J. Helbert, P. Wurz, I. Veselovsky, S. Orsini, and A. Milillo (2007), Mercury's surface composition and character as measured by ground-based observations, Space Sci. Rev., 132, 399-431, doi:10.1007/s11214-007-9221-3.

Sprague, A. L., K. L. Donaldson Hanna, R. W. H. Kozlowski, J. Helbert, A. Maturilli, J. B. Warell, and J. L. Hora (2009), Spectral emissivity measurements of Mercury's surface indicate Mg- and Ca-rich mineralogy, K-spar, Na-rich plagioclase, rutile, with possible perovskite, and garnet, Planet. Space Sci., 57, 364-383, doi:10.1016/j.pss.2009.01.006.

Strom, R. G., and A. L. Sprague (2003), Exploring Mercury: The Iron Planet, 216 pp., Springer-Praxis, Chichester, U.K

Vervack, R. J., Jr., W. E. McClintock, R. Killen, A. Sprague, B. J. Anderson, M. H. Burger, T. E. Bradley, N. Mouawad, S. C. Solomon, and N. R. Izenberg (2010), Mercury's complex exosphere: Results from MESSENGER's third flyby, Science, 329, 672-675, doi:10.1126/science. 1188572 .

Vilas, F. (1988), Surface composition of Mercury from reflectance spectrophotometry, in Mercury, edited by F. Vilas, C. R. Chapman, and M. S. Mathers, pp. 59-76, Univ. of Ariz. Press, Tucson, Ariz.

Waters, L. S. (Ed.) (2002), MCNPX users' manual version 2.4.0, Rep. LACP-02-408, Los Alamos Natl. Lab., Los Alamos, N.M.

Weider, S. Z., L. R. Nittler, R. D. Starr, T. J. McCoy, K. R. StockstillCahill, P. K. Byrne, B. W. Denevi, J. W. Head, and S. C. Solomon (2012), Chemical heterogeneity on Mercury's surface revealed by the MESSENGER X-ray Spectrometer, J. Geophys. Res., 117, E00L05, doi:10.1029/2012JE004153. 